\title{
AVALIAÇÃO DE BIOCOMBUSTÍVEL DERIVADO DO BIO-ÓLEO OBTIDO POR PIRÓLISE RÁPIDA DE BIOMASSA LIGNOCELULÓSICA COMO ADITIVO PARA GASOLINA
}

Carmen Luisa Barbosa Guedes*, Daniele Cristina Adão\#, Talita Pedroso Quessada, Dionísio Borsato e Olívio Fernandes Galão

Departamento de Química, Centro de Ciências Exatas, Universidade Estadual de Londrina, 86051-990 Londrina - PR, Brasil

Eduardo Di Mauro

Departamento de Física, Centro de Ciências Exatas, Universidade Estadual de Londrina, 86051-990 Londrina - PR, Brasil

Juan Miguel Mesa Pérez

Bioware Tecnologia, Rua Alcides Rosini Duarte da Conceição, 76, 13083-970 Campinas - SP, Brasil

José Dilcio Rocha

Empresa Brasileira de Pesquisa Agropecuária, Parque Estação Biológica, 70770-901 Brasília - DF, Brasil

Recebido em 6/2/09; aceito em 29/10/09; publicado na web em 26/3/10

\begin{abstract}
EVALUATION OF BIOFUEL DERIVED FROM LIGNOCELLULOSIC BIOMASS FAST PYROLYSIS BIO-OIL FOR USE AS GASOLINE ADDICTIVE. A biofuel was prepared from acid aqueous fraction $(\mathrm{pH}=2)$ of bio-oil produced by fast pyrolysis (Bioware Technology) of lignocellulosic biomass (sugar cane residue) and tested in blends (2, 5, 10 e 20\% v/v) with gasoline type $\mathrm{C}$ (common) marketed in Brazil. The specification tests made in the Refinery President Getúlio Vargas (PETROBRAS) showed increasing in the octane number (MON) and antiknock index (AKI) with reduction in the residue generation during the combustion. The physicochemical characteristics of the biofuel were similar that combustible alcohol allowing its use as gasoline additive.
\end{abstract}

Keywords: distillation curve; induction period; steam pressure.

\section{INTRODUÇÃO}

A demanda por energia está aumentando rapidamente, devido ao crescimento da população e seus anseios tecnológicos. A população mundial dedicou-se às indústrias de carvão e petróleo, mas com a exploração desenfreada de reservas naturais e a questão do efeito estufa, existe atualmente grande interesse para a produção sustentável de energia. As fontes de energia renováveis, como a biomassa, têm papel fundamental no contexto energético, ambiental e sócio-econômico. ${ }^{1}$

A biomassa consiste em elementos como carbono, hidrogênio, oxigênio e nitrogênio. $\mathrm{O}$ enxofre está presente em menores proporções e alguns tipos de biomassa contêm também porções significantes de espécies inorgânicas. ${ }^{2}$ As fontes de biomassa incluem madeira e resíduos de madeira, colheitas agrícolas e seus resíduos, resíduo sólido municipal, resíduos animais, resíduo de processamento de alimento, plantas aquáticas e algas. ${ }^{3}$ Os principais constituintes moleculares da biomassa são hemicelulose, celulose e lignina e um dos principais processos de conversão é a pirólise. ${ }^{4}$

Vários mecanismos já foram propostos para as possíveis rotas de reação que ocorrem durante a pirólise de biomassa. ${ }^{5-8} \mathrm{O}$ ácido acético é o principal produto da decomposição térmica. Durante a pirólise ocorre a formação de água por desidratação, de ácido acético pela eliminação de grupo acetila originariamente ligado a unidades de xilose, de furfural pela desidratação da xilose, de ácido fórmico a partir de grupos carboxílicos do ácido urônico e de metanol a partir de grupos metoxilas também do ácido urônico.

O processo de pirólise produz combustíveis líquidos com alto rendimento, ${ }^{9}$ porém, ainda existem alguns desafios que precisam ser enfrentados no uso destes produtos. O óleo resultante da pirólise de biomassa, denominado genericamente de bio-óleo, além de ser um

*e-mail: carmen@uel.br

"Endereço atual: Instituto de Tecnologia do Paraná, Rua Prof. Algacyr

Munhoz Mader, 3.775, 81350-010 Curitiba, PR, Brasil. combustível líquido renovável, sendo esta a principal vantagem sobre derivados do petróleo, pode ser usado para a produção de inúmeras substâncias químicas. ${ }^{10}$

O uso de derivados do bio-óleo como combustível em veículos de transporte é tecnicamente possível, mas existe a necessidade de pesquisas e investimentos. ${ }^{11-14}$ Pesquisas envolvendo separação e transformação de componentes de bio-óleo em ésteres, seja para caracterizar as reações e os produtos da pirólise, avaliando a estabilidade do produto durante a estocagem ou ainda, testar a mistura deste biocombustível em mistura com o diesel de petróleo ou a gasolina vêm sendo realizadas, ${ }^{15-21}$ seja com o objetivo de verificar a estabilidade do produto durante a estocagem ou avaliar o seu desempenho e possibilidade de uso em mistura com o combustível fóssil.

De acordo com a literatura no tema, os compostos oxigenados do bio-óleo, originários da pirólise de biomassa têm potencial para compor misturas com os combustíveis fósseis utilizados em veículos de transporte. A semelhança de características físicas e químicas das frações do bio-óleo com o álcool combustível comercializado no Brasil indica a possibilidade de uso destes em mistura com a gasolina, compondo um blender ou substituindo o álcool etílico anidro combustível (AEAC). ${ }^{18}$

Por questões de segurança, diversidade e sustentabilidade, como também para mitigação do efeito estufa, todos os países desenvolvidos e em desenvolvimento devem investir em pesquisa, tecnologia e inovação na busca de combustíveis a partir de fontes renováveis, não só apenas devido às emissões associadas ao uso de veículos ou motores estacionários, mas também buscando avaliar o ciclo de vida destes combustíveis. 22,23

Quanto à viabilidade tecnológica da cadeia produtiva no país, vários processos de conversão termoquímica e catalítica de biomassa lignocelulósica vêm sendo propostos e desenvolvidos com a participação de pesquisadores brasileiros, sendo que alguns destes processos já se mostraram eficientes como alternativa para obtenção de combustíveis líquido, sólido e gasoso. ${ }^{24-28}$ 
A viabilidade econômica e ambiental da produção de biocombustíveis por processos de termoconversão poderia ser otimizada, agregando valor aos resíduos agroindustriais e florestais. Na produção do álcool combustível, em média, cada tonelada de cana-de-açúcar produz $140 \mathrm{~kg}$ de bagaço e $140 \mathrm{~kg}$ de palha como resíduo. Na cadeia produtiva do biodiesel, também é gerado material lignocelulósico residual (palha, tronco, galhos, cascas e bagaço) proveniente das espécies oleaginosas. A elevada disponibilidade de biomassa lignocelulósica residual no Brasil tem papel importante na produção de energia utilizando fontes renováveis.

O presente trabalho teve como objetivo preparar os ésteres derivados do bio-óleo (pirólise de biomassa lignocelulósica) que pudessem constituir misturas ou emulsões estáveis com combustíveis fósseis, e avaliar a possibilidade de uso em veículo de transporte deste produto em mistura com a gasolina comum tipo $\mathrm{C}$, comercializada em Campinas, SP e Londrina, PR através de ensaios regulamentados pela Agência Nacional do Petróleo (ANP Portaria n³09, de 27/12/2001). ${ }^{29}$

\section{PARTE EXPERIMENTAL}

O bio-óleo ${ }^{30}$ utilizado nesse trabalho foi produzido a partir de bagaço e palha de cana-de-açúcar e gramínea do tipo capim elefante ${ }^{18,31}$ na Planta de Pirólise Rápida PPR-200 da empresa Bioware Tecnologia, ${ }^{32,33}$ incubada e graduada pela INCAMP (Incubadora de Empresas de Base Tecnológica da UNICAMP), Campinas, SP.

$\mathrm{O}$ método de extração da fração aquosa ácida $(\mathrm{pH}=2)$ do bio-óleo, a obtenção dos derivados por esterificação de Fischer e caracterização dos produtos estão descritos em Peláez-Samaniego, ${ }^{16}$ Adão ${ }^{18}$ e Rodríguez. ${ }^{31}$

O processo de tratamento para remoção de água do produto da esterificação de Fischer foi otimizado e realizado através de destilação após adição de $1 \%$ v/v de etileno glicol no Laboratório de Fluorescência e Ressonância Paramagnética Eletrônica (LAFLURPE) da Universidade Estadual de Londrina. ${ }^{18}$

O produto obtido por esterificação de Fischer, neste trabalho denominado biocombustível, foi misturado nas proporções de 2, 5 , 10 e $20 \%$ v/v com a gasolina comum tipo C, adquirida nas cidades de Campinas, SP e Londrina, PR.

A análise das misturas foi realizada de acordo com os métodos estabelecidos por Normas Brasileiras (NBR) e Métodos Brasileiros (MB) da Associação Brasileira de Normas Técnicas (ABNT) e/ou de normas da American Society for Testing and Materials (ASTM) em conformidade com a Agência Nacional de Petróleo (ANP Portaria 309, de 27/12/2001). ${ }^{29}$ Os dados relativos à precisão, repetitividade e reprodutibilidade, fornecidos nas Normas, foram utilizados como guia para aceitação das determinações em duplicata. Os ensaios foram realizados no Laboratório de Pesquisa e Análise de Combustíveis da Universidade Estadual de Londrina, Londrina, PR e/ou no Laboratório de Qualidade de Combustíveis da Refinaria Presidente Getulio Vargas, Araucária, PR.

\section{RESULTADOS E DISCUSSÃO}

Os principais componentes e as condições de processamento da biomassa atribuem papel importante na distribuição e nas propriedades dos produtos resultantes do processo de termoconversão. ${ }^{16} \mathrm{~A}$ celulose, polímero linear formado por unidades de glicose, produz por degradação térmica principalmente levoglucosan, glicolaldeído, 5-hidroximetil furfural, hidroxiacetaldeído, ácido acético, ácido fórmico e carvão, a maioria dos quais solúveis em água. Em se tratando da hemicelulose, polímero ramificado baseado em hexose, pentose e ácido glicurônico, esta é menos resistente termicamente e sua degradação origina os ácidos carboxílicos, que são a base para a obtenção do biocombustível utilizado neste trabalho. Quanto à lignina, polímero aromático constituído de guaiacila, siringila e $p$-hidroxifenila, origina os fenóis no bio-óleo e o carvão da pirólise.

A composição e as características da biomassa lignocelulósica que originou o bio-óleo utilizado neste trabalho foi avaliada quanto ao processo de termoconversão. ${ }^{16} \mathrm{~A}$ composição média do bagaço e da palha de cana-de-açúcar compreendem aproximadamente $40 \%$ de celulose; $23 \%$ e $32 \%$ de hemicelulose; $18 \%$ e $23 \%$ de lignina, respectivamente. $\mathrm{O}$ elevado teor de hemicelulose principalmente na palha de cana-de-açúcar é o principal responsável pelo alto rendimento de ácidos carboxílicos no bio-óleo e, consequentemente, pela alta porcentagem de ésteres no biocombustível. O capim elefante possui em média $30 \%$ de celulose e também de hemicelulose, e menos que $10 \%$ de lignina, contribuindo de forma significativa para o rendimento do bio-óleo.

O produto resultante da esterificação de Fischer sobre a fração aquosa $(\mathrm{pH}=2)$ do bio-óleo, contendo aproximadamente 67,5\% de ésteres (alifáticos $\mathrm{C}_{3}-\mathrm{C}_{8}$ e aromáticos) e outros constituintes oxigenados (éteres, aldeídos, cetonas e fenóis), apresentou 25,50\% (v/v) de água (ABNT NBR 15531); ${ }^{34}$ após o devido tratamento ${ }^{18}$ a porcentagem de água foi reduzida a $2,65 \%$ (v/v).

A considerável redução no teor de água possibilitou a solubilização e a mistura ou emulsão estável do produto (ésteres e outros oxigenados), que passou a ser denominado biocombustível, com a gasolina comum tipo $\mathrm{C}$, adquirida na cidade de Campinas, SP e Londrina, PR nas proporções de 2, 5, 10 e $20 \%$ v/v.

O biocombustível foi também testado em mistura com o óleo diesel comum interior, porém não ocorreu estabilização das emulsões, considerando as mesmas porcentagens avaliadas com a gasolina comum tipo C, adquirida na cidade de Campinas, SP e Londrina, PR. Na ocasião de aquisição dos combustíveis e realização dos ensaios, o diesel comercial não continha adição de biodiesel. A gasolina, por se tratar de gasolina comum tipo $\mathrm{C}$, não continha aditivo (detergente ou dispersante); e conforme legislação vigente na ocasião, possuía $20 \%$ de álcool etílico anidro combustível (AEAC).

$\mathrm{O}$ fato do biocombustível (ésteres alifáticos $\mathrm{C}_{3}-\mathrm{C}_{8}$ e aromáticos) não constituir emulsões estáveis com o diesel $\left(\mathrm{C}_{4}-\mathrm{C}_{12}\right)$ se deve à composição por hidrocarbonetos mais "pesados" do que aqueles existentes na gasolina $\left(\mathrm{C}_{4}-\mathrm{C}_{8}\right)$, além do que a gasolina comum tipo $\mathrm{C}$ contém álcool etílico anidro combustível, que deve agir como um dispersante, promovendo a formação de emulsão estável com o biocombustível.

O ensaio visual para determinação da cor, aspecto e presença ou não de impurezas nas amostras de gasolina tipo $\mathrm{C}$ contendo o biocombustível foi realizado em proveta de vidro, ${ }^{35}$ sendo possível observar que não houve qualquer alteração de cor ou aspecto do combustível fóssil, o qual se manteve incolor, de aspecto límpido e isento de impurezas.

\section{Curva de destilação}

Foi realizada a destilação (ABNT NBR 9619) ${ }^{36}$ das amostras de gasolina comum tipo C, comercializada em Campinas, SP e Londrina, PR, contendo $2,5,10$ e $20 \%$ v/v do biocombustível e as curvas registradas para as misturas de biocombustível com o combustível fóssil foram semelhantes à curva de destilação obtida para a respectiva amostra do combustível comercial (Figura 1).

Este ensaio para especificação da gasolina consiste na destilação de $100 \mathrm{~mL}$ de combustível, condensando o destilado e registrando as temperaturas e volumes das frações recolhidas. Os dados de temperatura, porcentagem de volume líquido de destilado e resíduo da destilação encontram-se na Tabela 1.

Todas as temperaturas e volumes registrados estiveram dentro dos limites estabelecidos pela legislação para a gasolina comum tipo C, comercializada no Brasil. 
O resíduo gerado na destilação das misturas com 2, 10 e $20 \%$ de biocombustível na gasolina de Campinas, assim como 2 e $20 \%$ de biocombustível na gasolina de Londrina, foi menor do que aquele resultante da destilação da gasolina comercializada nas respectivas localidades. Este resultado pode ser indicativo de que o biocombustível (ésteres e outros oxigenados) atue promovendo a combustão da gasolina e, deste modo, se utilizado em mistura com o combustível fóssil poderá reduzir o nível de emissões do monóxido de carbono pelos automóveis.

a)

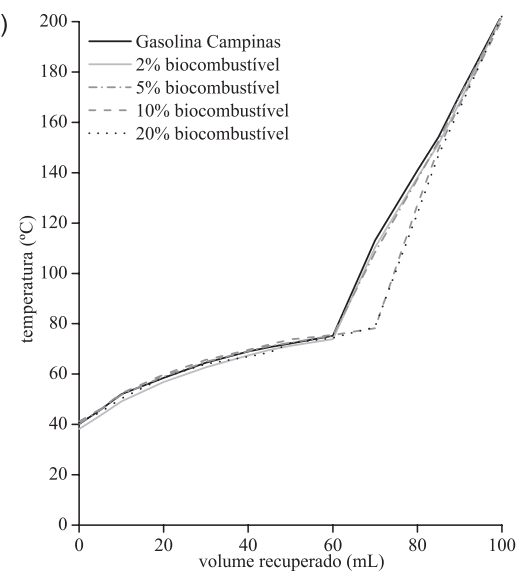

b)

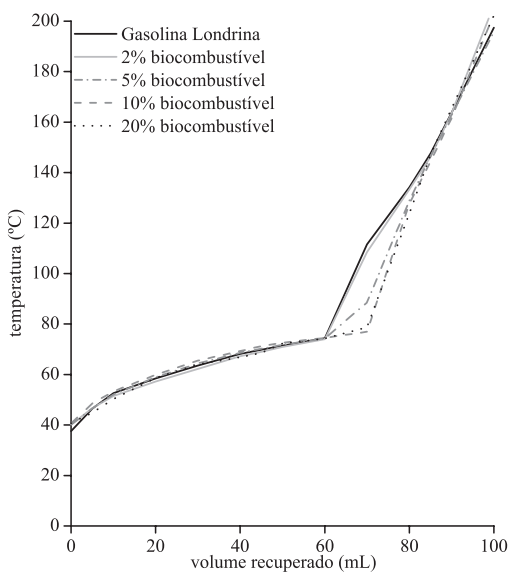

Figura 1. Diagramas de temperatura $\left({ }^{\circ} \mathrm{C}\right)$ versus volume $(\mathrm{mL})$ de destilado da gasolina comum tipo C em mistura com o biocombustível. (a) Gasolina comercializada na cidade de Campinas, SP contendo 2, 5, 10 e 20\% v/v do biocombustível. (b) Gasolina comercializada na cidade de Londrina, PR contendo $2,5,10$ e $20 \% \mathrm{v} / \mathrm{v}$ do biocombustivel

\section{Pressão de vapor}

As características da destilação, juntamente com a pressão de vapor, definem e controlam a partida do motor, seu aquecimento, aceleração, tendência ao tamponamento, diluição do óleo do carter e economia de combustível, bem como a tendência a provocar o congelamento no carburador, fenômeno que ocorre a baixas temperaturas em determinadas condições de umidade. Os combustíveis que se enquadram na especificação proporcionam partida rápida e fácil do motor em qualquer clima, boas características de aceleração ao veículo, menor tendência a causar tamponamento (vapor lock), principalmente, quando a temperatura ambiente é muito elevada, havendo formação de bolhas de vapor no sistema de injeção de combustível, impedimento a passagem do mesmo. A pressão de vapor é uma das propriedades físicas da gasolina mais importantes para avaliação do seu desempenho como combustível automotivo. ${ }^{37}$

A pressão de vapor ${ }^{38}$ tem grande importância também no armazenamento e no transporte do combustível, bem como no manuseio. A especificação deste parâmetro para a gasolina comum tipo C comercializada no Brasil é de no máximo $69,0 \mathrm{kPa}$ à temperatura de $37,8^{\circ} \mathrm{C}$. Encontram-se na Figura 2 os valores de pressão de vapor da gasolina comum tipo $\mathrm{C}$, comercializada nas cidades de Campinas e Londrina, assim como suas misturas contendo diferentes porcentagens do biocombustível.

A gasolina adquirida em Campinas apresentou pressão de vapor igual a $63,8 \mathrm{kPa}$, mantendo este valor constante na mistura com 2

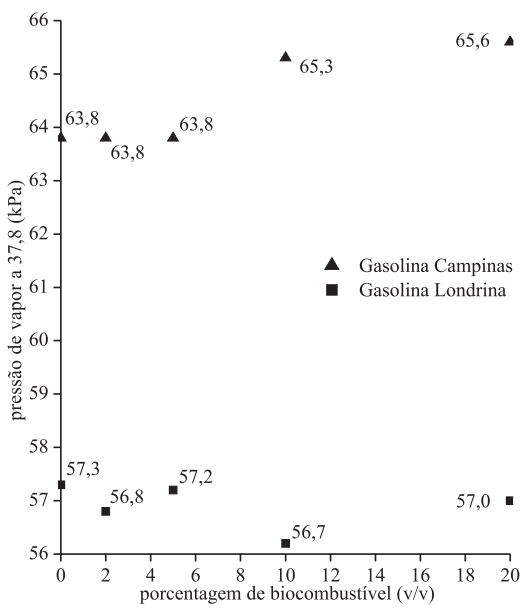

Figura 2. Pressão de vapor das amostras de gasolina comum tipo C comercializadas nas cidades de Campinas e Londrina contendo 2, 5, 10 e 20\% do biocombustivel

Tabela 1. Temperatura, porcentagem de destilado e resíduo da destilação das amostras de gasolina comum tipo C, adquirida em Campinas, SP e Londrina, PR com adição de 2, 5, 10 e $20 \%$ em volume do biocombustível

\begin{tabular}{|c|c|c|c|c|c|c|}
\hline $\begin{array}{l}\text { Combustível } \\
\text { comercial }\end{array}$ & $\begin{array}{c}\text { Porcentagem } \\
\text { de biocombustível }\end{array}$ & $\begin{array}{c}10 \% \text { evaporado } \\
\left({ }^{\circ} \mathrm{C}\right)\end{array}$ & $\begin{array}{c}50 \% \text { evaporado } \\
\left({ }^{\circ} \mathrm{C}\right)\end{array}$ & $\begin{array}{l}90 \% \text { evaporado } \\
\left({ }^{\circ} \mathrm{C}\right)\end{array}$ & $\begin{array}{l}\text { PFE } \\
\left({ }^{\circ} \mathrm{C}\right)\end{array}$ & $\begin{array}{c}\text { Resíduo da destilação } \\
\text { (\% volume })\end{array}$ \\
\hline \multirow{5}{*}{$\begin{array}{l}\text { Gasolina } \\
\text { comum tipo C } \\
\text { Campinas, SP }\end{array}$} & 0 & 51,9 & 72,1 & 170,7 & 202,7 & 1,15 \\
\hline & 2 & 49,2 & 71,3 & 167,8 & 202,3 & 1,13 \\
\hline & 5 & 51,8 & 72,5 & 170,1 & 201,8 & 1,18 \\
\hline & 10 & 52,3 & 73,7 & 166,9 & 200,7 & 1,13 \\
\hline & 20 & 53,6 & 71,9 & 170,1 & 203,8 & 1,10 \\
\hline \multirow{5}{*}{$\begin{array}{l}\text { Gasolina } \\
\text { comum tipo C } \\
\text { Londrina, PR }\end{array}$} & 0 & 52,7 & 71,4 & 163,7 & 197,5 & 1,23 \\
\hline & 2 & 51,4 & 70,9 & 163,4 & 206,3 & 1,08 \\
\hline & 5 & 52,1 & 71,8 & 162,7 & 195,9 & 1,23 \\
\hline & 10 & 53,3 & 72,5 & 161,5 & 202,9 & 1,25 \\
\hline & 20 & 54,5 & 72,2 & 168,6 & 204,1 & 1,13 \\
\hline $\begin{array}{l}\text { Especificação } \\
\text { ANP Portaria 309/2001 }\end{array}$ & & $65^{\circ} \mathrm{C}$ máximo & $80^{\circ} \mathrm{C}$ máximo & $\begin{array}{c}145^{\circ} \mathrm{C} \text { mínimo } 190{ }^{\circ} \mathrm{C} \\
\text { máximo }\end{array}$ & $220^{\circ} \mathrm{C}$ máximo & $\begin{array}{l}2 \% \\
\text { máximo }\end{array}$ \\
\hline
\end{tabular}


e 5\% do biocombustível. A adição de 10 e $20 \%$ de biocombustível provocou um acréscimo na pressão de vapor da gasolina comercial, atingindo $65,6 \mathrm{kPa}$ quando havia $20 \%$ de biocombustível em mistura com o combustível fóssil, todavia, sem comprometer a qualidade do produto comercial. Por outro lado, a adição do biocombustível em até $20 \%$ na gasolina adquirida em Londrina promoveu uma pequena diminuição na pressão de vapor do combustível comercial especificado com $57,3 \mathrm{kPa}$, ou seja, reduziu o valor para 57,0 kPa quando o combustível fóssil continha $20 \%$ de biocombustível.

Contudo, pequenas variações na pressão de vapor são desprezíveis considerando a volatilidade da gasolina e as características do ensaio. A adição do biocombustível à gasolina de Campinas e Londrina não causaria qualquer alteração no desempenho do combustível fóssil. No caso da gasolina, as condições do ensaio devem ser cuidadosamente estabelecidas e controladas, uma vez que podem ocorrer pequenas variações na temperatura, na quantidade de ar dissolvido e nas concentrações relativas de cada hidrocarboneto presente. A pressão de vapor para as gasolinas depende particularmente das concentrações relativas dos hidrocarbonetos que têm pontos de ebulição abaixo de $37,8^{\circ} \mathrm{C}$.

\section{Octanagem e IAD}

A octanagem da gasolina faz relação de equivalência à resistência de detonação de uma mistura percentual de isoctano $(2,2,4$ trimetilpentano) e n-heptano. Por convenção, o iso-octano recebeu o valor 100 e o n-heptano o valor zero, dado o seu baixo poder antidetonante. Motores mais potentes exigem maiores compressões e, por consequência, combustíveis mais resistentes à ignição espontânea. ${ }^{39} \mathrm{E}$ com o objetivo de regular o índice de octana que se utiliza no Brasil o álcool etílico anidro combustível (AEAC).

A capacidade antidetonante é uma característica importante para a gasolina, uma vez que não deve detonar por compressão e sim por centelhamento. Durante a compressão do ar e do combustível no motor, ocorre o aquecimento desta mistura gerando a formação de peróxidos e hidroperóxidos orgânicos, os quais promovem a detonação de acordo com o mecanismo cadeia-radical:

$\mathrm{RO}+{ }^{\bullet} \mathrm{OH} \rightarrow \mathrm{R}-\mathrm{O}-\mathrm{O}-\mathrm{H}$

Os radicais $\mathrm{RO}{ }^{*} e^{\circ} \mathrm{OH}$ ocasionam uma quebra adicional da cadeia de hidrocarbonetos, que levam à detonação. ${ }^{40} \mathrm{~A}$ detonação prematura do combustível reduz a potência do motor e a adição de compostos oxigenados à gasolina torna o combustível mais resistente às reações de decomposição que originam radicais, atribuindo assim uma resistência maior à detonação.

A estrutura química dos hidrocarbonetos do combustível tem enorme influência na tendência a causar detonação. As parafinas de cadeia linear têm menor resistência à detonação do que as parafinas de cadeia ramificada, as olefinas e hidrocarbonetos cíclicos. Os naftênicos (cíclicos saturados) têm maior tendência à detonação do que os aromáticos (cíclicos insaturados). Assim, a gasolina rica em hidrocarbonetos de cadeia normal e longa (parafínicos) é, em geral, a que possui maior tendência à detonação, apresentando baixos valores para o índice de octano. Contrariamente, gasolinas contendo alto teor de aromáticos e/ ou isoparafinas e elevado teor de olefinas possuem baixa tendência à detonação e, por conseguinte, altos valores de índice de octano.

Os ensaios de laboratório para determinar as características antidetonantes das gasolinas usam motor CFR (Cooperative Fuel Reserarch) monocilíndricos. O valor mínimo estabelecido para a octanagem MON (Motor Octane Number) da gasolina comum tipo Cé 82,0 , que corresponde à mesma resistência de uma mistura que contém $82 \%$ em volume de iso-octano e $18 \%$ em volume de $n$-heptano. A octanagem RON (Research Octane Number) não faz parte do quadro da especificação brasileira da gasolina automotiva dos tipos A ou C, constando apenas do quadro de especificações da gasolina padrão. A gasolina brasileira em mistura com o AEAC origina um combustível com ótimas características antidetonantes.

Quando se trata de definir a octanagem requerida pelos motores, alguns países, em se tratando da gasolina premium, adotam ao invés do número de octanagem MON ou RON, o Índice Antidetonante (IAD) como representativo do desempenho antidetonante do combustível para um universo mais amplo de veículos. O IAD é definido como a média entre as octanagens MON e RON, ou seja, IAD = $(\mathrm{MON}+\mathrm{RON}) / 2$.

Os valores de octanagem da gasolina encontram-se na Tabela 2. As octanagens $\mathrm{MON}^{41}$ e $\mathrm{RON},{ }^{42}$ assim como o IAD, foram calculadas tomando-se como base a gasolina comum Tipo C, comercializada em Campinas, SP e Londrina, PR, contendo 2, 5, 10 e $20 \%$ de biocombustível.

Tabela 2. Octanagem (MON e RON) e índice antidetonante (IAD) determinados para as misturas de 2, 5, 10 e 20\% do biocombustível com a gasolina comum tipo C comercializadas em Campinas, SP e Londrina, PR

\begin{tabular}{|c|c|c|c|c|}
\hline $\begin{array}{l}\text { Combustível } \\
\text { comercial }\end{array}$ & $\begin{array}{c}\text { Biocombustível } \\
(\% \mathrm{v} / \mathrm{v})\end{array}$ & $\begin{array}{l}\text { Octanagem } \\
\text { MON }\end{array}$ & $\begin{array}{l}\text { Octanagem } \\
\text { RON }\end{array}$ & IAD \\
\hline \multirow{5}{*}{$\begin{array}{l}\text { Gasolina comum } \\
\text { tipo C Campinas, } \\
\text { SP }\end{array}$} & 0 & 82,0 & 94,9 & 88,5 \\
\hline & 2 & 82,5 & 95,2 & 88,9 \\
\hline & 5 & 83,0 & 95,9 & 89,5 \\
\hline & 10 & 84,3 & 96,9 & 90,6 \\
\hline & 20 & 86,1 & $>100$ & nd \\
\hline \multirow{5}{*}{$\begin{array}{l}\text { Gasolina comum } \\
\text { tipo C Londrina, } \\
\text { PR }\end{array}$} & 0 & 82,3 & 94,9 & 88,6 \\
\hline & 2 & 82,8 & 95,2 & 89,0 \\
\hline & 5 & 83,2 & 96,1 & 89,7 \\
\hline & 10 & 84,1 & 97,1 & 90,6 \\
\hline & 20 & 86,8 & $>100$ & nd \\
\hline \multicolumn{2}{|c|}{$\begin{array}{l}\text { Especificação ANP Portaria } \\
309 / 2001\end{array}$} & 82,0 mínimo & $*$ & 87,0 mínimo \\
\hline
\end{tabular}

* Valor não especificado pela legislação brasileira. nd - não detectado

A incorporação do biocombustível à gasolina $\mathrm{C}$ comercializada em Campinas e Londrina proporcionou aumento gradativo na octanagem do combustível fóssil, devido ao acréscimo de compostos oxigenados, os quais devem estabilizar radicais ${ }^{\circ} \mathrm{OH}$ gerados no aquecimento da mistura ar-combustível no motor, diminuindo a probabilidade de transferência de energia por hidrocarbonetos menos estáveis presentes no combustível fóssil. De forma semelhante ao álcool, o biocombustível oxigenado atribuiu características antidetonantes à gasolina, o que proporcionaria maior potência ao motor Ciclo Otto (motor de 4 tempos com explosão por centelha) com mínimo de consumo.

É também conhecido que gasolinas contendo alto teor de aromáticos possuem baixa tendência à detonação e, por conseguinte, altos valores de índice de octano. Neste sentido, os derivados fenólicos do bio-óleo, embora em baixa concentração no biocombustível, além de outros aromáticos, podem estar contribuindo para aumentar a octanagem da gasolina comum Tipo C, comercializada em Campinas e Londrina.

Além disto, o biocombustível devido à sua composição química pode atribuir características detergentes e/ou dispersantes ao combustível fóssil, o que deve proporcionar altas taxas de compressão e alto desempenho, além de minimizar a formação de depósitos nos bicos injetores, evitando o acúmulo dos resíduos de combustão.

\section{Período de indução e formação de goma}

O ensaio ${ }^{43}$ foi realizado com amostras da gasolina comum tipo $\mathrm{Cem}$ mistura com 2, 5, 10 e $20 \%$ do biocombustível. Os períodos de indução 
determinados para a gasolina adquirida em Campinas e Londrina, assim como para as misturas contendo biocombustível foram acima de 720 min, indicando que a adição do biocombustível à gasolina comercial não alterou a estabilidade da mesma no que diz respeito a este parâmetro.

Este método para verificar tendência à formação de goma durante a armazenagem provoca o envelhecimento prematuro da gasolina ao submetê-la à ação do oxigênio, a uma pressão de $7,0 \mathrm{kgf} / \mathrm{cm}^{2}$ e temperatura de $100{ }^{\circ} \mathrm{C}$ durante um tempo mínimo de $360 \mathrm{~min}$. O tempo decorrido entre o início do ensaio e aquele em que ocorre uma nítida queda de pressão é chamado "período de indução", o qual assegura a armazenagem do combustível sem que haja formação de uma quantidade apreciável de goma.

A formação de goma na gasolina é decorrente da polimerização de hidrocarbonetos insaturados do combustível pelo aquecimento, apresentando-se como material resinoso sólido ou semi-sólido que pode se converter em uma espécie de verniz, restringindo o fluxo de combustível. A presença desse material resinoso acarreta sérios problemas que diminuem o rendimento do motor. ${ }^{44}$ Íons metálicos no etanol podem também promover a formação de gomas e sedimentos em motores que utilizam a mistura etanol-gasolina como combustível. A principal fonte de contaminação do etanol combustível por espécies metálicas são os processos corrosivos sofridos pelas colunas de destilação, reservatórios das destilarias e até de postos de combustível.

A especificação da ANP para a formação de goma na gasolina é de no máximo $5 \mathrm{mg}$ de resíduo por $100 \mathrm{~mL}$ de amostra. A gasolina comum tipo $\mathrm{C}$, adquirida em Campinas e Londrina, assim como as amostras em mistura com 2, 5, 10 e $20 \%$ de biocombustível foram analisadas ${ }^{45}$ e apresentaram $1 \mathrm{mg}$ de resíduo, indicando que o biocombustível não favoreceu ou inibiu a formação de goma na gasolina.

\section{Teor de álcool}

O álcool etílico anidro combustível (AEAC) é um dos aditivos da gasolina comercial, devido a sua propriedade antidetonante. Esta propriedade impede que a mistura ar/combustível se inflame antes do ponto de maior compressão do cilindro no motor. O teor de AEAC na mistura carburante é competência do Ministério de Agricultura, Pecuária e Abastecimento (MAPA Resolução nº 30, de 15/05/2003). ${ }^{46}$ O teor de álcool na gasolina varia, historicamente, entre 13 e $25 \%$ em volume. Na ocasião de aquisição das amostras e realização dos ensaios, a porcentagem de AEAC especificada para a gasolina comum tipo C comercializada em Campinas e Londrina era de $20 \% \pm 1 \mathrm{v} / \mathrm{v}$ (CIMA Resolução n³5, de 22/02/2006). ${ }^{47}$

Os resultados obtidos na determinação do teor de álcool ${ }^{48}$ e outros componentes oxigenados, nas amostras de gasolina comum tipo $\mathrm{C}$ contendo 2, 5, 10 e 20\% de biocombustível, encontram-se na Tabela 3 .

O cálculo para determinação da porcentagem em volume (\% v/v) de compostos oxigenados nas gasolinas contendo o biocombustível foi realizado utilizando-se a equação: $V^{\prime \prime}=2 \times\left(V^{`}-50 m l\right)+1 \%$, onde $V^{\prime}$ "é o volume corresponde a compostos oxigenados em $50 \mathrm{~mL}$ de amostra a ser analisada (20\% AEAC + \% biocombustível), e V'é o volume final da fase aquosa (solução de $\mathrm{NaCl}+\mathrm{AEAC}+$ biocombustível).

A adição de $2 \%$ de biocombustível à gasolina não alterou o teor de álcool no combustível fóssil. Adicionando-se 5 e $10 \%$ de biocombustível à gasolina comum tipo C (20\% de AEAC), adquirida em Campinas e Londrina, observou-se um aumento na porcentagem de compostos oxigenados para 22 e $24 \%$, respectivamente. Considerando a mistura de $20 \%$ do biocombustível à gasolina comercial de Campinas e Londrina, o teor de oxigenados determinado foi de $28 \%$. Atualmente, a gasolina comum tipo C é especificada com $25 \%$ de AEAC pelo Conselho Interministerial do Açúcar e do Álcool (CIMA) através da Resolução n ${ }^{\circ} 37$, de 27/06/2007. ${ }^{49}$ A margem de erro admissível é $1 \%$, conforme disposto no Art. $9^{\circ}, \S 2^{\circ}$, da Lei
Tabela 3. Porcentagem em volume de AEAC e outros compostos oxigenados presentes na gasolina comum tipo $\mathrm{C}^{*}$ em mistura com 2, 5, 10 e $20 \%$ do biocombustível

\begin{tabular}{lcc}
\hline $\begin{array}{l}\text { \% de biocombustível } \\
(\mathrm{v} / \mathrm{v})\end{array}$ & $\begin{array}{c}\text { \% de AEAC e outros compostos oxigenados (v/v) } \\
\text { Gasolina Campinas-SP }\end{array}$ & \begin{tabular}{c} 
Gasolina Londrina-PR \\
\hline 0
\end{tabular} \\
20 & 20 & 20 \\
5 & 22 & 20 \\
10 & 24 & 22 \\
20 & 28 & 24 \\
\hline
\end{tabular}

*Amostras adquiridas na cidade de Campinas, SP e Londrina, PR em 2006, quando o teor do AEAC no combustível fóssil foi de $20 \% \pm 1 \mathrm{v} / \mathrm{v}$.

Federal n ${ }^{\circ} 10.203$, de 22/02/2001, que trata da redução de emissão de poluentes por veículos automotores. ${ }^{50}$

Devido as suas características polares semelhantes ao álcool etílico, o biocombustível foi submetido a ensaios especificados pela Agencia Nacional de Petróleo (ANP Portaria 126, de 08/08/2002) ${ }^{51}$ para comercialização do Álcool Etílico Anidro Combustível (AEAC) e do Álcool Etílico Hidratado Combustível (AEHC). Os resultados encontrados para massa específica, condutividade elétrica e teor alcoólico estão na Tabela 4.

Tabela 4. Parâmetros físico-químicos determinados no biocombustível de acordo com a especificação do álcool combustível no Brasil

\begin{tabular}{|c|c|c|c|c|c|}
\hline \multirow{2}{*}{$\begin{array}{l}\text { Parâmetros } \\
\text { analisados }\end{array}$} & \multirow{2}{*}{$\begin{array}{l}\text { Métodos de } \\
\text { ensaio }\end{array}$} & \multirow{2}{*}{ Resultado } & \multicolumn{2}{|c|}{ Especificação } & \multirow{2}{*}{ Unidade } \\
\hline & & & AEAC & AEHC & \\
\hline $\begin{array}{l}\text { Massa específica } \\
\text { a } 20^{\circ} \mathrm{C}\end{array}$ & $\begin{array}{l}\text { ABNT NBR } \\
5992^{52}\end{array}$ & 808,3 & 791,5 máx. & $\begin{array}{l}807,6 \\
\text { a } 811,0\end{array}$ & $\mathrm{~kg} / \mathrm{m}^{3}$ \\
\hline $\begin{array}{l}\text { Condutividade } \\
\text { elétrica }\end{array}$ & $\begin{array}{c}\text { ABNT NBR } \\
10547^{53}\end{array}$ & 136,6 & 500 máx. & 500 máx. & $\mu \mathrm{S} / \mathrm{m}$ \\
\hline Teor alcoólico & $\begin{array}{c}\text { ABNT NBR } \\
5992^{52}\end{array}$ & 93,6 & 99,3 mín. & 92,6 a 93,8 & ${ }^{\circ}$ INPM \\
\hline
\end{tabular}

A massa específica do biocombustível enquadra-se apenas na especificação do AEHC, diferente da massa específica do AEAC devido, provavelmente, a traços de água ainda presente no biocombustível, elevando sua massa específica. Em se tratando do teor alcoólico, o biocombustível mais uma vez se enquadra na especificação do AEHC. A condutividade elétrica do biocombustível é baixa e, portanto, possui a vantagem de não corroborar para a corrosão de chapas metálicas de aço carbono, o que seria uma grande vantagem para seu uso em motores.

O fato do biocombustível, aqui avaliado, formar misturas estáveis com a gasolina comum tipo $\mathrm{C}$, pode ser justificado por sua interação com o álcool etílico anidro combustível que compõe a gasolina comercializada no Brasil. Principalmente devido à ausência de componente polar na gasolina A padrão (isenta de álcool) e no diesel automotivo comercializado nas cidades de Londrina e Campinas, não foi possível misturar o biocombustível para obter emulsões estáveis.

\section{CONCLUSÃO}

A partir do processo de pirólise (tecnologia Bioware) utilizando biomassa lignocelulósica (bagaço e palha de cana-de-açúcar e gramínea) foi produzido o bio-óleo utilizado como matéria-prima neste estudo. O produto da esterificação de Fischer, sobre a fração aquosa $(\mathrm{pH}=2)$ do bio-óleo $\left(67,5 \%\right.$ de ésteres alifáticos $\mathrm{C}_{3}-\mathrm{C}_{8}$ e aromáticos, éteres, aldeídos, cetonas e fenóis), foi tratado para redução do teor de água e misturado à gasolina comum tipo $\mathrm{C}$ comercializada nas cidades de Campinas, SP e Londrina, PR (teor de AEAC $=20 \% \pm 1$ ) nas proporções de 2, 5, 10 e $20 \%$ v/v constituindo emulsões estáveis.

De acordo com os resultados dos ensaios físico-químicos es- 
tabelecidos pela ANP, o biocombustível apresentou características semelhantes ao álcool combustível e, em alguns casos, com melhor desempenho devido às suas características químicas. Observou-se um aumento significativo na octanagem MON ou RON e no IAD da gasolina comercial contendo o biocombustível. A cada $2 \%$ em volume de biodiesel adicionado houve um incremento de 0,5 na octanagem MON das gasolinas. As curvas de destilação das gasolinas contendo 2, 5, 10 e 20\% de biocombustível apresentaram parâmetros dentro dos limites de especificação, inclusive no que diz respeito à geração de resíduos. Os resultados dos ensaios para verificar período de indução e formação de goma confirmaram a especificação do combustível comercial com adição do biocombustível.

Comprovada sua viabilidade técnica, uma possibilidade de uso do biocombustível seria incorporá-lo à gasolina padrão através de uma mistura com o AEAC totalizando $25 \%$ no combustível fóssil, de acordo com a legislação vigente para adição de álcool à gasolina comercial.

\section{AGRADECIMENTOS}

À Bioware pelo fornecimento do bio-óleo; à Refinaria Presidente Getulio Vargas pela realização dos ensaios especificados para gasolina comercial; ao TECPAR pela oportunidade de treinamento à mestranda D. C. Adão; ao CNPq pela Bolsa ITI/A 120607/2005-0 à graduanda T. P. Quessada e pelo apoio financeiro no EDITAL CNPq 21/2004 RHAE Inovação/Tipo C.

\section{REFERÊNCIAS}

1. Demirbas, A.; Energy Convers. Manage. 2008, 8, 2106.

2. Yaman, S.; Energy Convers. Manage. 2004, 45, 651.

3. Demirbas, A.; Energy Convers. Manage. 2001, 42, 1357.

4. Bridgwater, A. V.; Meier, D.; Radlein, D.; Org. Geochem. 1999, 30, 1479.

5. Demirbas, A.; Energy Convers. Manage. 2000, 41, 633.

6. Tsai, W. T.; Lee, M. K.; Chang, Y. M.; J. Anal. Appl. Pyrolysis 2006, 76, 230.

7. Demirbas, A.; Progress Energy Combus. Sci. 2007, 33, 1.

8. Demirbas, A.; Fuel Process. Technol. 2007, 88, 591.

9. Oasmaa, A.; Czernik, S.; Energy Fuels 1999, 13, 914.

10. Czernik, S.; Bridgwater, A. V.; Energy Fuels 2004, 18, 590.

11. Demirbas, M. F.; Balat, M.; Energy Convers. Manage. 2006, 47, 2371.

12. Mohan, D.; Pittman Jr., C. U.; Steele, P. H.; Energy Fuels 2006, $20,848$.

13. Qi, Z.; Jie, C.; Tiejun, W.; Ying, X.; Energy Convers. Manage. 2007, 48, 87.

14. Ji-Lu, Z.; J. Anal. Appl. Pyrolysis 2008, 83, 205.

15. Junming, X.; Jianchun, J.; Yunjuan, S.; Yanju, L.; Biomass Bioenergy 2008, 32, 1056.

16. Peláez-Samaniego, M. R.; Dissertação de Mestrado, Universidade Estadual de Campinas, Brasil, 2007.

17. Calabria, R.; Chiariello, F.; Massoli, P.; Exp. Ther. Flui. Sci. 2007, 31, 413.

18. Adão, D. C.; Dissertação de Mestrado, Universidade Estadual de Londrina, Brasil, 2006.

19. Ikura, M.; Stanciulescu, M.; Hogan, E.; Biomass Bioenergy 2003, 24, 221.

20. Diebold, J. P.; Review of the Chemical and Physical Mechanisms of the Storage Stability of Fast Pyrolysis Bio-Oils, NREL, 2000, Report No. SR-570-27613.

21. Diebold, J. P.; Czernik, S.; Energy Fuels 1997, 11, 1081.

22. Hoekman, S. K.; Renewable Energy 2009, 34, 14.

23. Chiaramonti, D.; Oasmaa, A.; Solantausta, Y.; Renewable Sustainable Energy Rev. 2007, 11, 1056.

24. Martins, A. F.; Diniz, J.; Stahl, J. A.; Cardoso, A. L.; Quim. Nova 2007, 30,873 .
25. Barbosa, L. C. A.; Maltha, C. R. A.; Silva, V. L.; Colodette, J. L.; Quim. Nova 2008, 31, 2035.

26. Suarez, P. A.; Moser, B. R.; Sharma, B. K.; Erhan, S. Z.; Fuel 2008, 88 , 1143

27. Wiggers, V. R.; Wisniewski Jr., A.; Madureira, L. A. S.; Barros, A. A. C.; Meier, H. F.; Fuel 2009, 88, 2135.

28. Figueiredo, M. K. -K.; Romeiro, G. A.; Ďavila, L. A.; Damasceno, R. N.; Franco, A. P.; Fuel 2009, 88, 2193.

29. Agência Nacional do Petróleo; ANP Portaria ${ }^{\circ} 309$, de 28 de dezembro de 2001, Diário Oficial da União, 27/12/2001.

30. Rocha, J. D.; Luengo, C.; Br PI 9.804.166-5, 1998.

31. Rodriguez, R. A. V.; Uso da biomassa como energia limpa e matériaprima renovável. Bioware, Campinas, 2006. Relatório Científico. http://www2.uel.br/grupo-pesquisa/meioambiente/fotopetro/arquivos/ relatorios/relatorio01.pdf, acessada em Março 2010.

32. Mesa-Pérez, J. M.; Cortez, L. A. B.; Rocha, J. D.; Gomez, E. O.; Revista Analytica 2003, 4, 32.

33. Mesa-Pérez, J. M.; Tese de Doutorado, Universidade Estadual de Campinas, Brasil, 2004.

34. ABNT; NBR 15531:2007 Álcool etílico - Determinação do teor de água - Método volumétrico de Karl Fischer.

35. ABNT; NBR 7148:2001 Petróleo e produtos de petróleo - Determinação da massa específica, densidade relativa e ${ }^{\circ} \mathrm{API}$ - Método do densímetro.

36. ABNT; NBR 9619:2005 Produtos de Petróleo - Determinação da faixa de destilação.

37. Souza, A. M.; Dissertação de Mestrado, Universidade Federal da Bahia, Brasil, 2004.

38. ABNT; NBR 14156:2006 Determinação da pressão de vapor - Mini Método.

39. Perdih, A.; Perdih, F.; Acta Chim. Slov. 2006, 53, 306.

40. Saidakhmedov, S. I.; Kapustin, V. M.; Saidakhmedov, A. I.; Chem. Technol. Fuels Oils 2006, 42, 120.

41. ASTM; D 2700:1999 Standard test method for motor octane number of spark-ignition engine fuel.

42. ASTM; D 2699:1999 Standard test method for research octane number of spark-ignition engine fuel.

43. ABNT; NBR 14478:2006 Gasolina - Determinação da estabilidade à oxidação pelo método do período de indução.

44. Teixeira, L. S. G.; Souza, J. C.; Santos, H. C.; Pontes, L. A. M.; Guimarães, P. R. B.; Vitor Sobrinho, E.; Vianna, R. F.; Fuel Process. Technol. 2007, 88, 73.

45. ABNT; NBR 14525:2006 Combustíveis - Determinação de goma por evaporação.

46. Conselho Interministerial do Açúcar e do Álcool - CIMA; Resolução $n^{\circ} 30$, de 15 de maio de 2003. Dispõe sobre a adição de álcool etílico anidro combustível à gasolina, Diário Oficial da União, 27/05/ 2003.

47. Conselho Interministerial do Açúcar e do Álcool - CIMA; Resolução no 35, de 22 de fevereiro de 2006. Dispõe sobre a adição de álcool etílico anidro combustível à gasolina, Diário Oficial da União, 23/02/2006.

48. ABNT; NBR13992 Gasolina automotiva - Determinação do teor de álcool etílico anidro combustível.

49. Conselho Interministerial do Açúcar e do Álcool - CIMA; Resolução $n^{\circ} 37$, de 27 de junho de 2007. Dispõe sobre a adição de álcool etílico anidro combustível à gasolina, Diário Oficial da União, 28/06/07.

50. Lei Federal $n^{\circ}$ 10.203, de 22 de fevereiro de 2001. Dispõe sobre a redução de emissão de poluentes por veículos automotores, e dá outras providências, Diário Oficial da União, 23/02/2001.

51. Agência Nacional do Petróleo - ANP; Portaria $n^{\circ} 126$, de 08 de agosto de 2002, Diário Oficial da União, 09/08/2002.

52. ABNT; NBR 5992:2007 Determinação da massa específica e do teor alcoólico do Álcool Etílico e suas misturas com água.

53. ABNT; NBR 10547:2007 Álcool Etílico - Determinação da condutividade elétrica. 